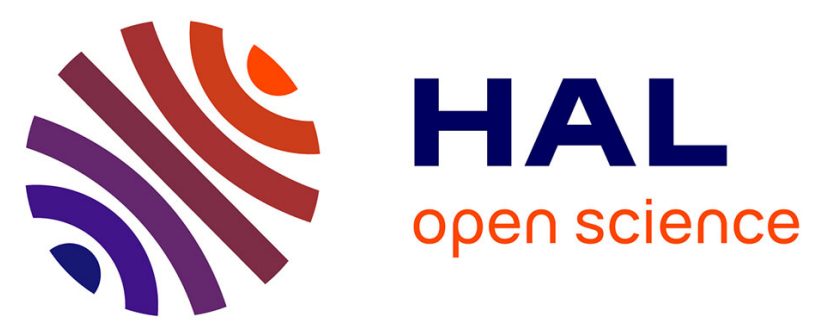

\title{
Use of ring-disc electrodes for the determination of aqueous solutions of sulphur-containing compounds: thiols, disulphides, sulphides, thiol-esters, proteins and various inorganic ions
}

Francis Rauwel, Daniel R. Thevenot

\section{To cite this version:}

Francis Rauwel, Daniel R. Thevenot. Use of ring-disc electrodes for the determination of aqueous solutions of sulphur-containing compounds: thiols, disulphides, sulphides, thiol-esters, proteins and various inorganic ions. Bioelectrochemistry and Bioenergetics, 1976, 3, pp.284 - 301. 10.1016/03024598(76)80011-6 . hal-01179315

\section{HAL Id: hal-01179315 \\ https://hal.science/hal-01179315}

Submitted on 22 Jul 2015

HAL is a multi-disciplinary open access archive for the deposit and dissemination of scientific research documents, whether they are published or not. The documents may come from teaching and research institutions in France or abroad, or from public or private research centers.
L'archive ouverte pluridisciplinaire HAL, est destinée au dépôt et à la diffusion de documents scientifiques de niveau recherche, publiés ou non, émanant des établissements d'enseignement et de recherche français ou étrangers, des laboratoires publics ou privés. 


\title{
Use of Ring-dise Electrodes for the Determination of Aqueous Solutions of Sulphur-Containing Compounds: Thiols, Disulphides, Sulphides, Thiol-Esters, Proteins and Various Inorganic Ions*
}

\author{
by Francis Raunel and Daniel Thévenot
}

Laboratoire d’Energétique Biochimique, Université Paris-Val de Marne, Avenue du Général de Gaulle, 940ro Créteil Cedex, France

\section{Summary}

We examined the possibility of using nascent bromine and iodine, generated and detected on ring-disc electrodes, for the titration of aqueous solutions of thiols (ethanethiol, 2-methyl-2-propanethiol, ethanedithiol, I,3-propanedithiol, glutathione, ergothioneine, coenzyme-A), disulfides (dimethyl- and diethyldisulfide, cystine, oxidized form of glutathione and of lipoïc acid), sulfides (diethylsulfide, methionine), thiolesters (ethylthiol acetate, acetylcoenzyme-A) and various inorganic sulfur-containing compounds (sulfhydric acid, sulfite and thiosulfate). According to the shape of ring current $v s$ disc current curves, which is related to the rate of the reaction involved in the titration, we used different methods to analyse these curves and to determine the concentration of the compound. Most of them can be detected at a concentration as low as o.I $\mu M$ and titrated with a few per cent accuracy when their concentration is larger than $5 \mu M$. We discuss the influence of $\mathrm{pH}$ on the characteristics of the titration curves.

\section{Introduction}

Bromine and iodine are commonly used in volumetric titrations of organic compounds such as phenols, amines and thiols. Instead of this usual technique, some of these titrations can be performed by generating nascent halogen on the disc of a ring-disc electrode and by detecting the unreacted halogen on the ring. ${ }^{1 a, 1 b, 2 a}$ This method is fast, sensitive, nondestructive and allows to operate with small-volume samples. We tried to apply it to aqueous solutions of sulfur-containing compounds and

* Presented at the 3rd International Symposium on Bioelectrochemisty, Jülich, 27-3 I October I975. 
especially to the biological ones for which these qualities are of particular interest: disulfides, thiols, sulfides, proteins and thiolesters.

The halogen is generated on the disc by oxydation of the bromide or iodide contained in the solution :

$$
\text { (disc) } \quad 2 \mathrm{X}^{-} \rightarrow \mathrm{X}_{2}+2 \mathrm{e}^{-}
$$

Under the rotation of the electrode, the nascent halogen reaches the ring which is set at a suitable potential for its complete reduction:

$$
\text { (ring) } \quad \mathrm{X}_{2}+2 \mathrm{e}^{-} \rightarrow 2 \mathrm{X}^{-}
$$

When the solution is free from chemicals which can react with the halogen during its transit from disc to ring, the observed ring current $I_{r}$ is proportional to the monitored disc current $I_{d}$. But if compounds such as those listed above are present in the solution, the halogen reacts before reaching the ring. $I_{r}$ vs $I_{d}$ curves of different types may then be obtained, more particularly according to the mechanism and to the kinetics of this reaction.

In the case of a very fast bimolecular reaction (curve $I I$ of Fig. I) - such as the reaction between $\mathrm{As}(\mathrm{III})$ and $\mathrm{Br}_{2}$ - the concentration $c$ of the titrated compound is determined by the value $I_{d, \mathrm{o}}$ of the disc current at which the asymptote crosses the $I_{d}$ axis. This value is proportional to $c$ and the ratio between $I_{d, \mathrm{o}}$ and $c$ can be either calculated or determined with solutions of known concentration. ${ }^{2 a}$

If the reaction involved in the titration is a first-order one and is not very fast, the $I_{r}$ vs $I_{d}$ lines are straight near the origin and their slope

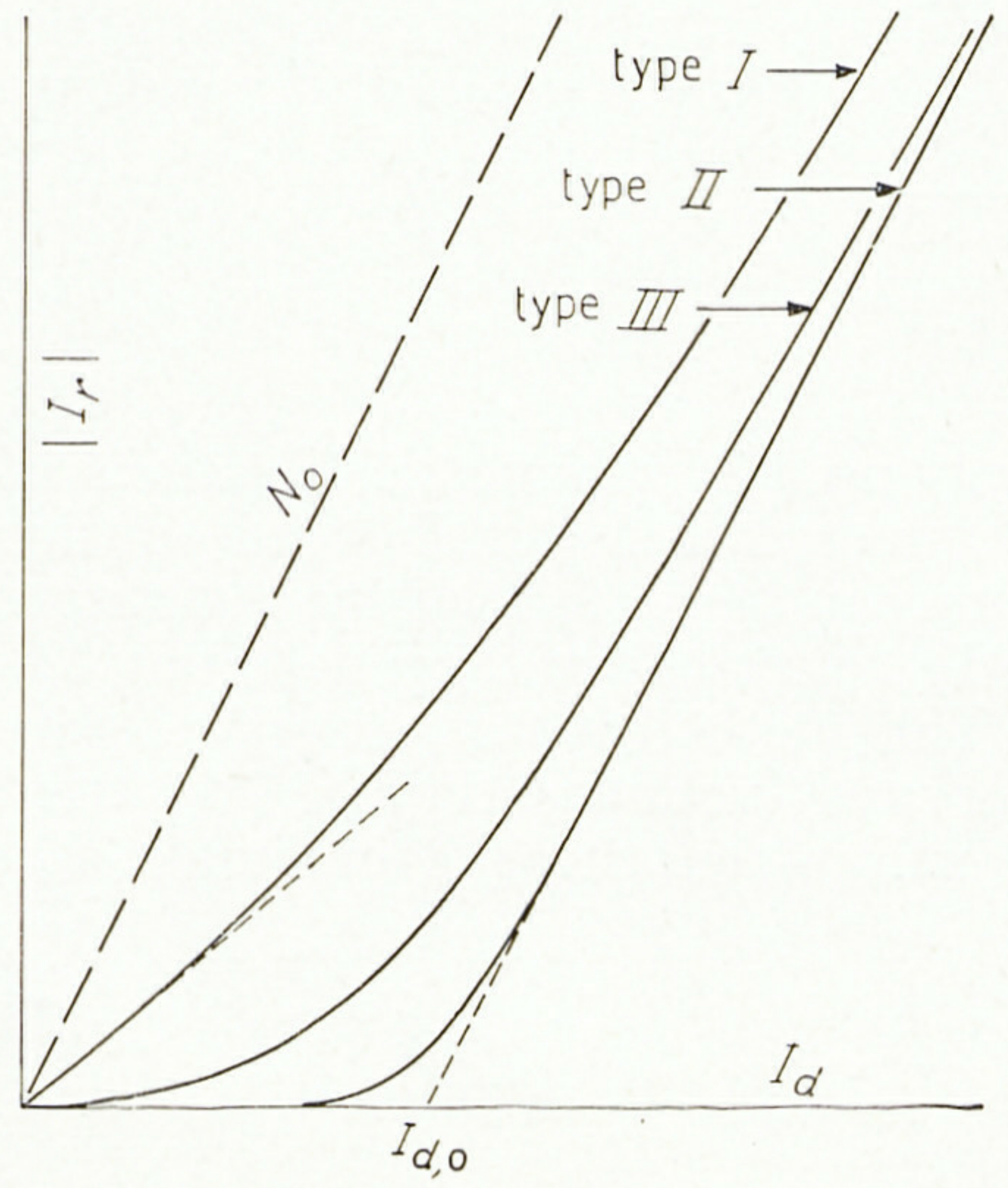

Fig. I.

Ring current $v s$. disc current shapes of curves obtained during titration of sulfurcontaining compounds by nascent halogen. Type $I$, rather slow titration reactions; type $I I$, fast titration reactions; type $I I I$, rather fast or complex titration reactions. 
is different from zero ${ }^{2 b}$ (curve $I$ of Fig. I). The slope of these lines depends on $c$ but also on the reaction rate. So it is necessary to calibrate $I_{r} v s I_{d}$ curves with solutions of known concentration to determine $c$.

\section{Experimental}

Reagents

Water has been distillated in an all glass still. All chemicals used to prepare the buffers were of an analytical reagent-grade quality. Buffer components were for $\mathrm{pH}=0.3,0.5 M$ sulfuric acid; for $\mathrm{pH}=4.7$, o. I $M$ potassium acetate and $0 . \mathrm{I} M$ acetic acid; for $\mathrm{pH}=5$.0, o.I $M$ dipotassium phthalate and o.I $M$ monopotassium phthalate; for $\mathrm{pH}=5.6$, O.I $M$ dipotassium citrate and $0 . \mathrm{I} M$ monopotassium citrate, and for $\mathrm{pH}=6.7$, o.I $M$ dipotassium phosphate and O.I $M$ monopotassium phosphate.

Dimethyl disult de and glutathione were purchased from Merck; ethanethiol, diethyl sulfide, $L$-tryptophane, ethyl thioacetate from ScHuCHARDT ; 2-methyl-2-propanethiol and $L$-cysteine-hydrochloride monohydrate from FLUKA; diethyl disulf de from K \& K LABORATORIES; $L$-ergothioneine, oxidized form of $D L-\alpha$-lipoïc acid and ovalbumine (grade V), from Sigma; coenzyme-A and acetyl-coenzyme-A from Boehringer ; ethanedithiol from J. T. BAKer; I,3-propanedithiol and oxidized form of glutathione from ALDRICH ; $L$-cystine, $D L$-methionine and $L$-tyrosine from SERLABo ; sodium sulfur, sodium sulfide and sodium thiosulfate from Prolabo. All these chemicals of analytical reagentgrade quality were used without further purification.

\section{Materials}

A Tacussel bipotentiostat (Bipad type I) and monitor (Servovit Io or G S T P 2) allow to make linear sweeps of the disc potential or current (the ring being set at a constant potential) or to make linear sweeps of the ring potential (the disc potential or current being constant). Disc and ring potentials were checked by comparison to $\mathrm{Ag} \mid \mathrm{AgCl}$, saturated $\mathrm{KCl}$ reference electrode (TACUSSEL $\mathrm{AgCl}$ IO) with an electronic millivoltmeter (TAcussel S $6 \mathrm{~N}$ ). Ring current vs disc current curves were drawn on a GOERTZ recorder (Servogor XY). The platinum disc - platinum ring electrode used was constructed and generously provided by Cocouelet (Electricité de France). Dimensions (disc radius I.98 40.05 $\mathrm{mm}$, inner ring radius $2 . \mathrm{I} 2 \pm 0.05 \mathrm{~mm}$, outer ring radius $2.37 \pm 0.05 \mathrm{~mm}$ ) were measured on a photograph enlargement where a length reference also appeared (slide calipers opened at $\mathrm{I} \pm 0.05 \mathrm{~cm}$ ).

The rotation speed of the d.c. motor driving the electrode was monitored by a TACussel Asservitex at $38.2 \mathrm{~Hz}$ unless special specifications are given. The rotation speed was checked with a JAQUET revolution counter. 
Cells were thermostated at I5.0 $\pm 0.2^{\circ} \mathrm{C}$ unless other specifications are given. The initial volume of the buffered solutions was $200 \mathrm{~cm}^{3}$ except for experiments on small volume samples $\left(25\right.$ and $\left.5 \mathrm{~cm}^{3}\right)$.

\section{Procedure}

The ring-disc electrode surface was frequently polished using emery and diamond papers $(3 \mu$ and $0.3 \mu)$. Before each series of recordings, the disc was submitted to repeated current sweeps until a reproducible $I_{r}$ vs $I_{d}$ blank line was obtained with a solution of potassium bromide or iodide $(0 . \mathrm{I}-0.5 \mathrm{M})$. The disc current sweep rate (usually 60 s per sweep) was such that the curve was identical on the return scan. The ring potential was adjusted to a value suitable to obtain a low ring-current background when $I_{d}$ equals zero (generally +0.2 V vs. N.H.E.). The ring-potential was always low enough to allow the complete reduction of the halogen. Under these conditions, except in the case of bromide solution at $\mathrm{pH}=6.7$ (phosphate buffer), the observed $I_{r} v s I_{d}$ blank lines were straight. In a phosphate buffer at $\mathrm{pH}=6.7$, oxidation of the platinum disc occurs at a lower potential than in an acid medium and interferes with the generation of bromine on the disc: $I_{r}$ vs $I_{d}$ lines are then somewhat curved. After polishing the electrode, $I_{r}$ vs $I_{d}$ blank straight lines are perfectly reproducible except for the first two sweeps of the disc current. The slopes $N_{0}$ of these lines differ by less than $2 \%$ when bromine or iodine is generated on the disc if the electrode is polished in the meanwhile. Polishing the electrode in fact causes the $N_{0}$ value to fluctuate within \pm IO $\% . \quad N_{0}$ is absolutely independent of the bromide or iodide concentration and decreases slightly when the temperature increases $\left(-4 \%\right.$ between I5 to $25^{\circ} \mathrm{C}$ ) : the calculated value of $N_{0} 0.256$, according to AlBery and BRUCKEnstein theory ${ }^{3}$ is in good agreement with its measured values $0.269 \pm 0.020$ at $25^{\circ} \mathrm{C}$ (average of 8 experiments at various rotation rates of the electrode, bromide concentrations and ring potentials).

After the initial disc current scans, small amounts of the studied compound was syringed into the cell and $I_{r}$ vs $I_{d}$ titration curves by nascent bromine was recorded. Titration by nascent iodine was performed afterwards by simple addition of potassium iodide, which is oxidized at a lower potential than bromide.

\section{Determination of the number of halogen molecules involved in the titration reaction}

The $I_{r}$ vs $I_{d}$ curves were compared to those obtained with As(III) solutions of equal concentration. As the oxidation of one mole of As(III) with bromine and iodine requires one mole of halogen, this comparison gives the number of halogen molecules involved in the reaction or an estimate of this number when the curves are of the type III (Fig. I). Incidentally, titration of As(III) by nascent bromine may be performed in both acid and neutral media, whereas titration by nascent iodine is 
only possible in neutral or slighty acid medium, As(III) being a stronger oxidant than iodine at $\mathrm{pH}=\mathrm{o}$.

The value $I_{d, \mathrm{o}}$ of the disc current at which the asymptote crosses the $I_{d}$-axis is given by $:^{2 a}$

$$
I_{d, \mathrm{o}}=\frac{r_{1}^{2} n_{d} \boldsymbol{F} D^{2 / 3} \omega^{1 / 2} \beta^{2 / 3}}{0.205 \nu^{1 / 6} N_{\mathrm{o}}} c
$$

where $r_{1}$ is the disc radius, $n_{d}$ the number of electrons exchanged on the disc, $\boldsymbol{F}$ the faraday, $D$ the diffusion coefficient of the reacting halogen, $\omega$ the rotation rate in $\mathrm{Hz}, v$ the kinematic viscosity of the solution and

$$
\beta=\left[\frac{r_{3}}{r_{1}}\right]^{3}-\left[\frac{r_{2}}{r_{1}}\right]^{3}
$$

with $r_{2}$ and $r_{3}$ indicating the inner and outer radius of the ring. We have checked, on titration of As(III) by nascent bromine and iodine, that $I_{d, \mathrm{o}}$ is proportional to $\omega^{1 / 2}(4-36 \mathrm{~Hz})$ and $c($ IO $\mu M-5 \mathrm{mM})$ and independent of the halide concentration (o.I-0.5 M). We have observed that $I_{d, \mathrm{o}}$ increases linearly with temperature $\left(+\mathrm{I} .95 \pm 0.05 \%{ }^{\circ} \mathrm{C}^{-1}\right.$ in the $\mathrm{I}^{-2} 5^{\circ} \mathrm{C}$ range) : this is probably related to the infuence of temperature on diffusion coefficients (about $+2 \%{ }^{\circ} \mathrm{C}^{-1}$ ). ${ }^{4}$ Furthermore $I_{d, \mathrm{o}}$ is significantly larger with bromine than with iodine as expected by the comparison of the apparent diffusion coefficients $\bar{D}$ of the reacting species i.e. $\mathrm{Br}_{2}+\mathrm{Br}_{3}-$ on one hand and $\mathrm{I}_{2}+\mathrm{I}_{3}{ }^{-}$on the other. Indeed, at $25^{\circ} \mathrm{C}$

$$
x=\frac{\left[\mathrm{X}_{3}-\right]}{\left[\mathrm{X}_{3}\right]}
$$

is in the range of $1.6-8$ and $3 \mathrm{I}-\mathrm{I} 60$ respectively for bromine and iodine when $\left[\mathrm{X}^{-}\right]$is in the range 0.I-0.5 M. The apparent dffusion coefficients of halogen in such mixtures

$$
\bar{D}=\frac{D_{\mathrm{x}_{2}}+x D_{\mathrm{x}_{3}}{ }^{-}}{\mathrm{I}-x}
$$

equals, with our halide concentration range, I. $36 \pm 0.02^{5}$ and I.I3 $\mathrm{cm}^{2} \mathrm{~s}^{-16}$ respectively for bromine and iodine. Indeed the measured value of the ratio

$$
\frac{\left(I_{d, \mathrm{o}}\right)_{\mathrm{Br}}}{\left(I_{d, \mathrm{o}}\right)_{\mathrm{I}}}=\mathrm{I} . \mathrm{I} 7
$$


is in good agreement with the calculated value

$$
\left(\frac{\bar{D}_{\mathrm{Br}}}{\bar{D}_{\mathrm{I}}}\right)^{2 / 3}=\text { I.I3. }
$$

\section{Results and discussion}

For each compound, titrations with nascent bromine and iodine were performed successively by recording a set of $I_{r} v s I_{d}$ curves in aqueous solutions of increasing concentrations (usually I $\mu M$ to o.I $\mathrm{m} M$ ). The rate of the reaction involved in the titration and thus the shape of the $I_{r}$ vs $I_{d}$ curves depends on the $\mathrm{pH}$, on the reactant (bromine or iodine) generated on the disc and on the titrated compound.

\section{Different types of ring current vs disc current curves}

The $I_{r}$ vs $I_{d}$ lines may present the shape of curve $I$ of Fig. I, with a slope different f:om zero near the origin. This first type of curve is typical of a reaction, the rate of which is limited by a rather slow step. As this slope allows to determine first-order reaction rates, ${ }^{2 b}$ we assumed some of these reactions to be of the first order and calculated an estimate of their velocity (Tables I and 2).

The $I_{r}$ vs $I_{d}$ lines may also present the shape of curve $I I$ of Fig. I (type $I I$ ) with a well-defined asymptote, parallel to the blank straight line of slope $N_{0}$, as expected for fast bimolecular reactions. ${ }^{2 a}$

Lastly, the $I_{r}$ vs $I_{d}$ lines may have the shape of curve $I I I$ of Fig. I (type III) with an ill-defined asymptote. This type of curve is intermediate between curves of type $I$ and $I I$ and probably corresponds either to titration reactions not fast enough to give a curve of type $I I$ or to a fast initial step followed by rather slow ones.

\section{Disulfides (RSSR)}

Iodine formed and detected on a ring-disc electrode has been found not to react significantly with all disulfides studied either in acid or neutral medium (Table I). This is consistent with the generally accepted formation of disulf:de during thiol oxidation with iodine ${ }^{7-10}$ while it is in contradiction with the possibility of volumetric titration of $L$-cystine by iodine. ${ }^{11}$

In acid solutions of $\mathrm{pH}=0.3$, nascent bromine reacts rapidly with dimethyl- and diethyl- disulf.des (titration curves of type II), rather slowly with the oxidized form of glutathione (type $I$ ) while its reaction is hardly noticeable with $L$-cystine (Table I). An increase to 6.7 in the $\mathrm{pH}$ of the solution enhances the rates of the last two reactions, especially the cystine oxidation: corresponding $I_{r}$ vs $I_{d}$ curves which belong to type $I$ (Fig. 2) may then be used for titration by the determination of their slope near origin (Fig. 3). We have also tested the oxidation by 


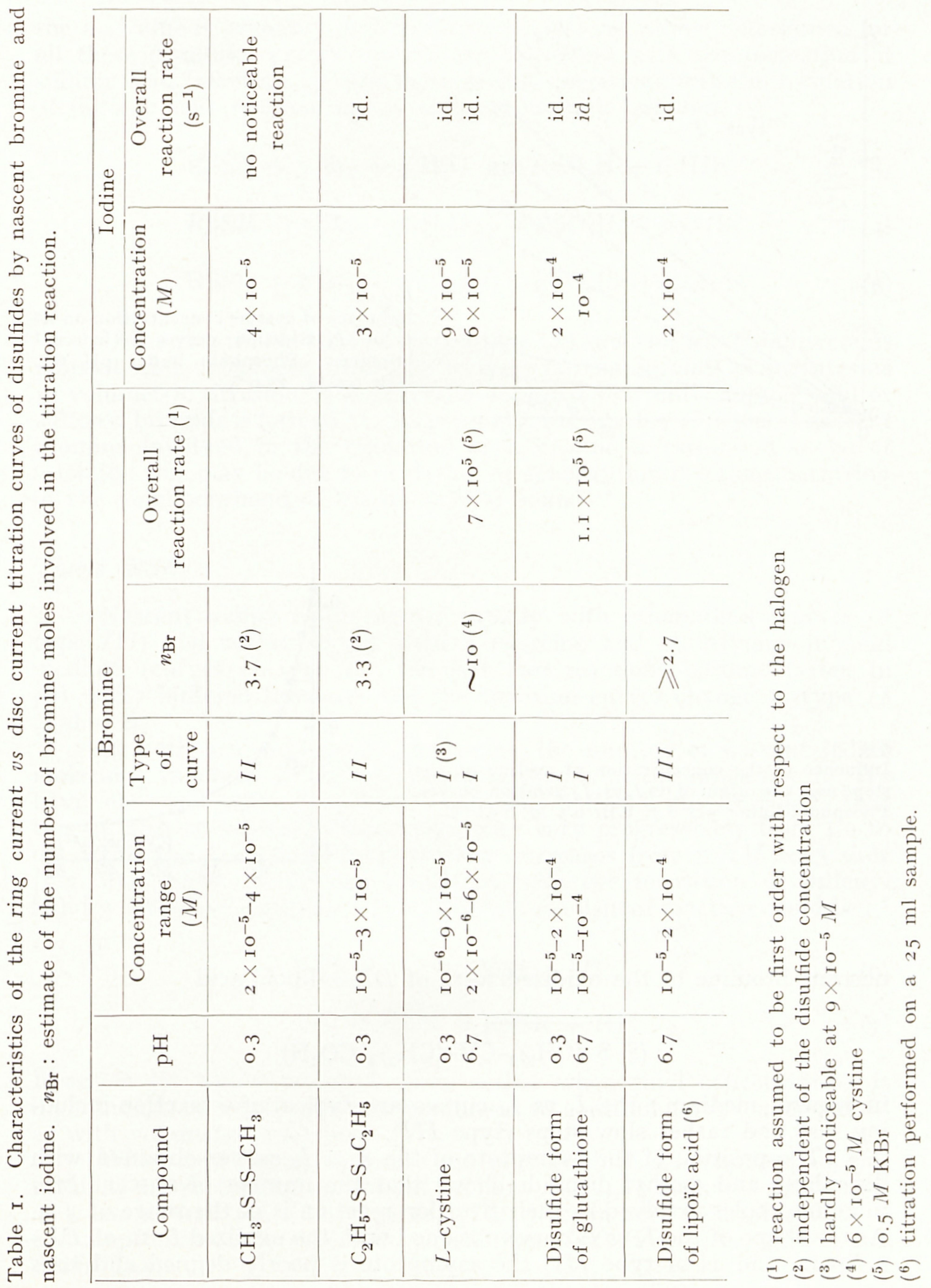




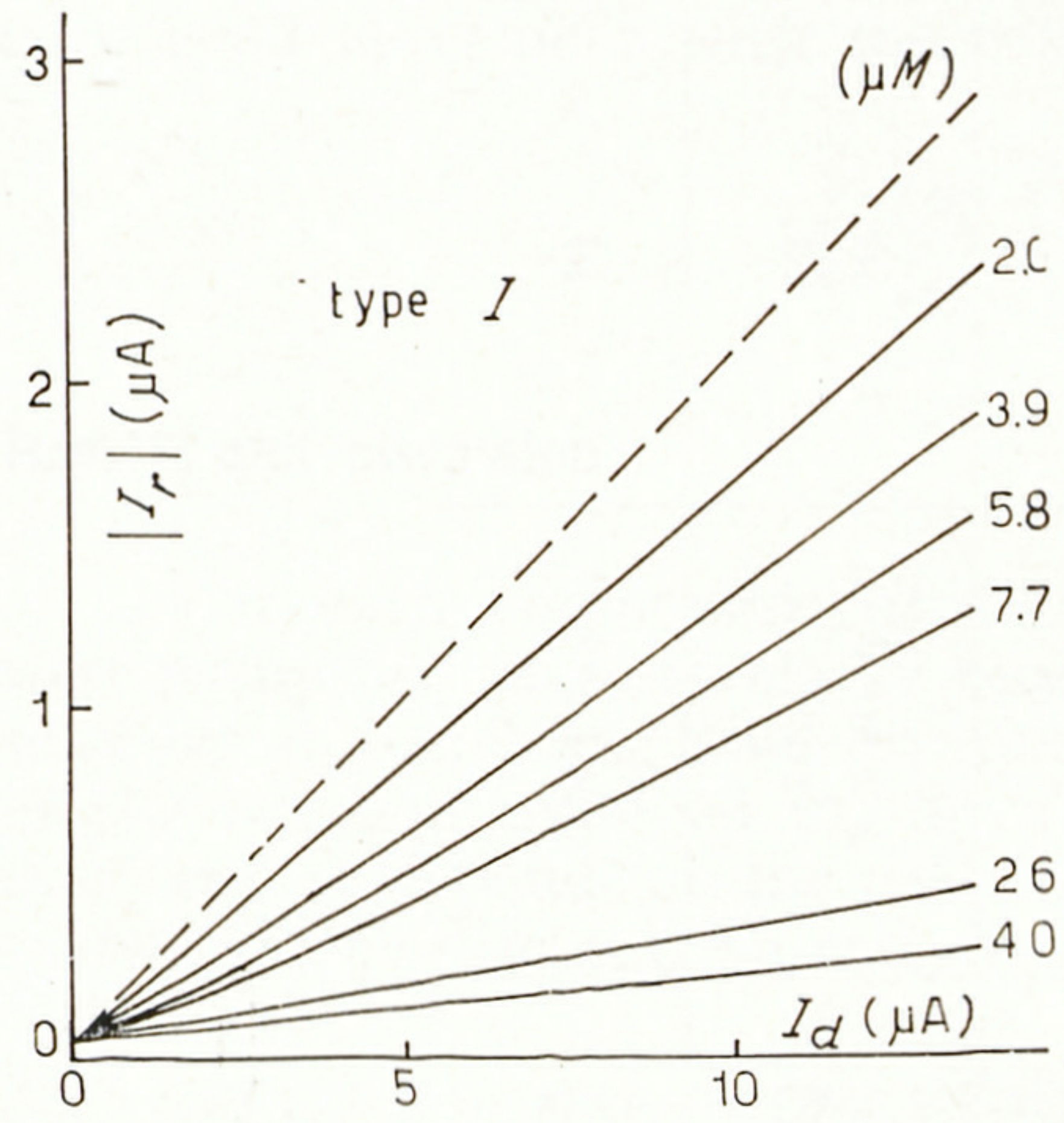

Fig. 3.

Influence of the concentration of cystine on the slope near the origin of its $I_{r} v s . I_{d}$ titration curves. Phosphate buffer $\mathrm{pH} 6.7, \mathrm{KBr} 0.5 \mathrm{M}$, I $5.0^{\circ} \mathrm{C}$.
Fig. 2.

Influence of cystine concentration on its $I_{r}$ vs. $I_{d}$ titration curves by nascent bromine. Phosphate buffer $\mathrm{pH}$ 6.7, $\mathrm{KBr} 0.5 M$, $\mathrm{I}_{5} . \mathrm{O}^{\circ} \mathrm{C}$.

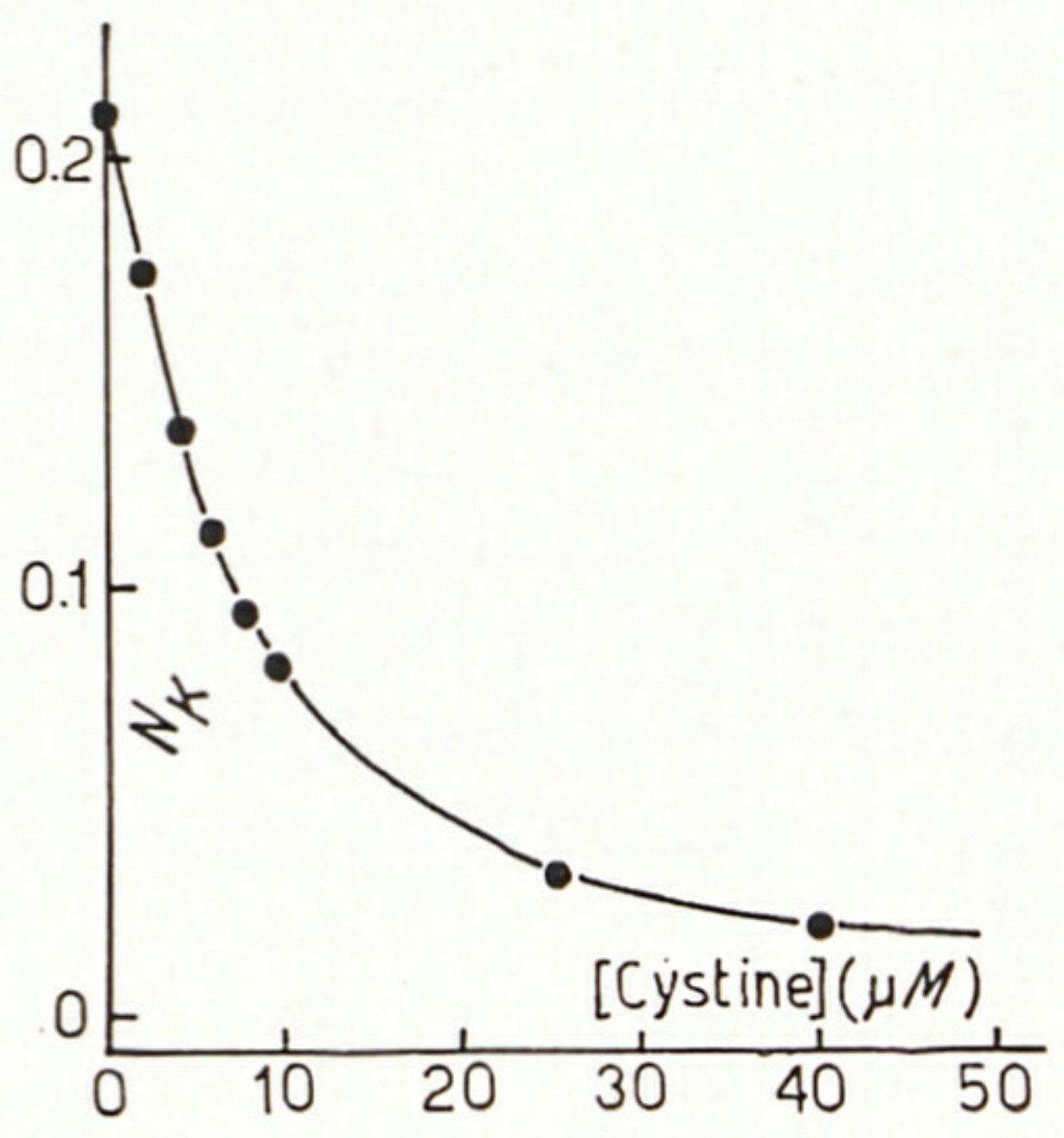

nascent bromine of the oxidized form of $D L-\alpha$-lipoïc acid

$$
\left(\mathrm{S}-\mathrm{S}-\left(\mathrm{CH}_{2}\right)_{2}-\mathrm{CH}-\left(\mathrm{CH}_{2}\right)_{4}-\mathrm{CO}_{2} \mathrm{H}\right)
$$

in neutral medium: the $I_{r}$ vs $I_{d}$ curves are typical of a reaction including fast and rather slow steps (type $I I I$ ).

The position of the asymptote of the $I_{r} v s I_{d}$ curves obtained with dimethyl- and diethyl disulfide shows that the number of nascent bromine molecules involved in their titration reaction is in the range of $3-4$. As the shape of the $I_{r}$ vs $I_{d}$ curve obtained with the oxidized form of $D L-$ $\alpha$-lipoïc acid is of type III, the asymptote is poorly defined and thus 
the $n_{\mathrm{Br}}$ value is probably underestimated. The $n_{\mathrm{Br}}$ values determined for all these disulfides except cystine are consistent with the formation of sulfinic acid [reaction (3)] and more or less consistent with the formation of sulfonic acid [reaction (4)] or sulfonyl bromide [reaction (5)] :

$$
\begin{aligned}
& \mathrm{RSSR}+3 \mathrm{Br}_{2}+4 \mathrm{H}_{2} \mathrm{O} \rightarrow 2 \mathrm{RSO}_{2} \mathrm{H}+6 \mathrm{HBr} \\
& \mathrm{RSSR}+5 \mathrm{Br}_{2}+6 \mathrm{H}_{2} \mathrm{O} \rightarrow 2 \mathrm{RSO}_{3} \mathrm{H}+\mathrm{IO} \mathrm{HBr} \\
& \mathrm{RSSR}+5 \mathrm{Br}_{2}+4 \mathrm{H}_{2} \mathrm{O} \rightarrow 2 \mathrm{RSO}_{2} \mathrm{Br}+8 \mathrm{HBr}
\end{aligned}
$$

If the reaction is allowed to continue not only for some milliseconds (transit time of halogen from disc to ring) but for seconds or minutes as in volumetric titration, it is generally accepted that only sulfonic acid or sulfonyl bromide is formed. ${ }^{12}$ Surprisingly, the number of moles of nascent bromine involved in the oxidation of $L$-cystine is estimated to be at least Io : this may be due to oxidation or substitution reactions occurring in the neighbourhood of the disulphide bound. ${ }^{13}$

\section{Thiols $(R S H)$}

Nascent iodine reacts rather rapidly with ethanethiol (curves of type $I I I)$ and rather slowly with $L$-cysteine and glutathione in acid medium (curves of type $I$ ) ; the last two reactions become faster in $\mathrm{pH}=6.7$ buffered solutions and the titration curves change to type $I I$ (Table 2).

In both acid and neutral solutions, the number of nascent iodine molecules involved in the titration reactions is in the range $0.5^{-I}$. We have observed with $L$-cysteine solutions, buffered at $\mathrm{pH}=6.7$, that this number of nascent iodine moles may vary progressively from I.o to 0.5 when the $L$-cysteine concentration increases from $5 \mu M$ to $5 \mathrm{~m} M$ (Fig. 4). These results are consistent with the formation of sulfenyl iodides (RSI) and disulfides. A possible mechanism of reaction could be : ${ }^{7}$

$$
\begin{aligned}
& \mathrm{RSH}+\mathrm{I}_{2} \rightarrow \mathrm{RSI}+\mathrm{HI} \\
& \mathrm{RSI}+\mathrm{RSH} \rightarrow \mathrm{RSSR}+\mathrm{HI}
\end{aligned}
$$

Reaction (7) would probably occur either when thiol concentration is high enough or when oxidation is allowed to continue for a longer period as with volumetric titrations. ${ }^{7-10}$

When titrations of ethane- and propanethiol, L-cysteine and glutathione are performed by nascent bromine, the $I_{r}$ vs $I_{d}$ curves are typical of a fast overall reaction (type $I I)$ (Fig. 5, 6) in acid medium and of a fast step followed by rather slow ones (type $I I I$ ) (Fig. 7) in neutral medium (Table 2). 


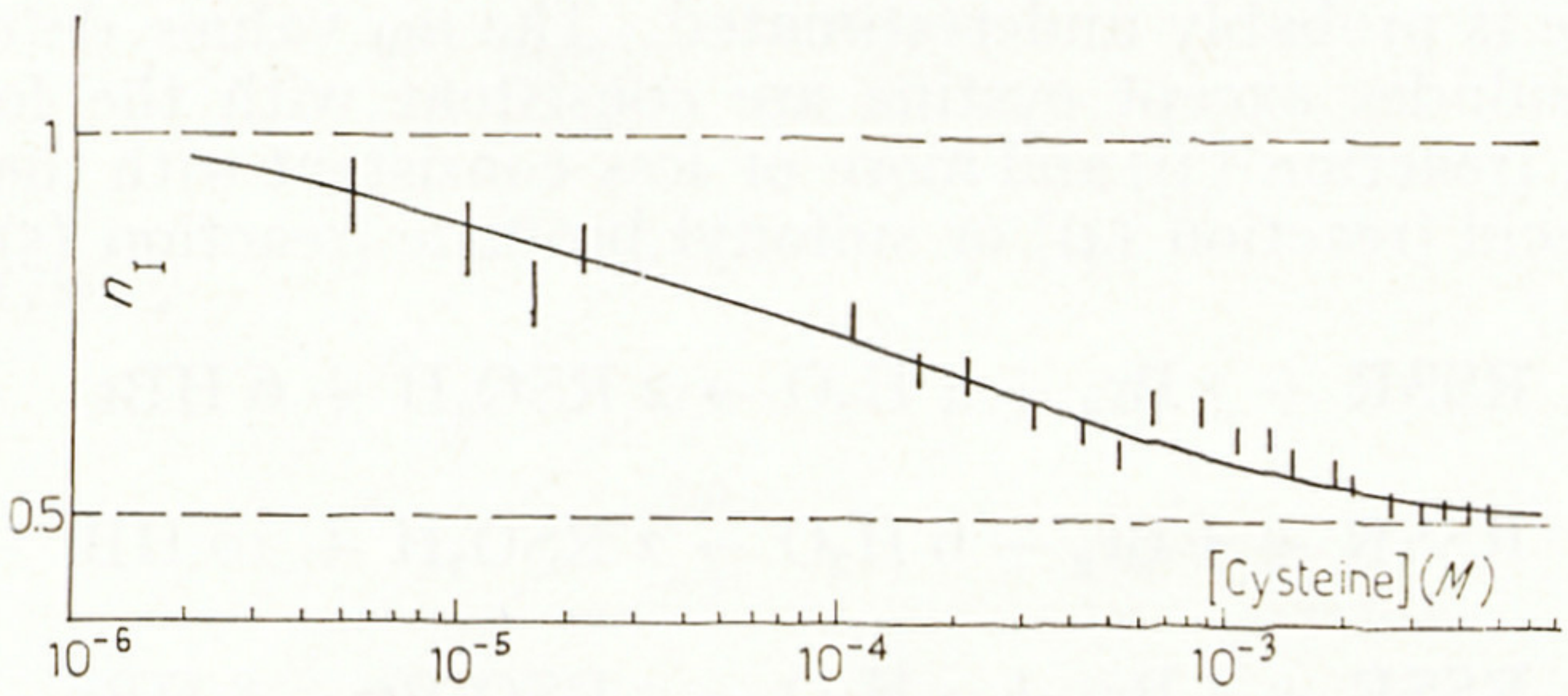

Fig. 4.

Influence of cysteine concentration on the stoechiometry of its titration reaction with nascent iodine. $n_{\mathrm{I}}$ : number of iodine molecule involved in the reaction determined by comparison of $I_{r} v s$. $I_{d}$ titration curves of $\mathrm{As}(\mathrm{III})$ in the same conditions. Phosphate buffer $\mathrm{pH} 6.7$, KI o.I $M, 20{ }^{\circ} \mathrm{C}$.

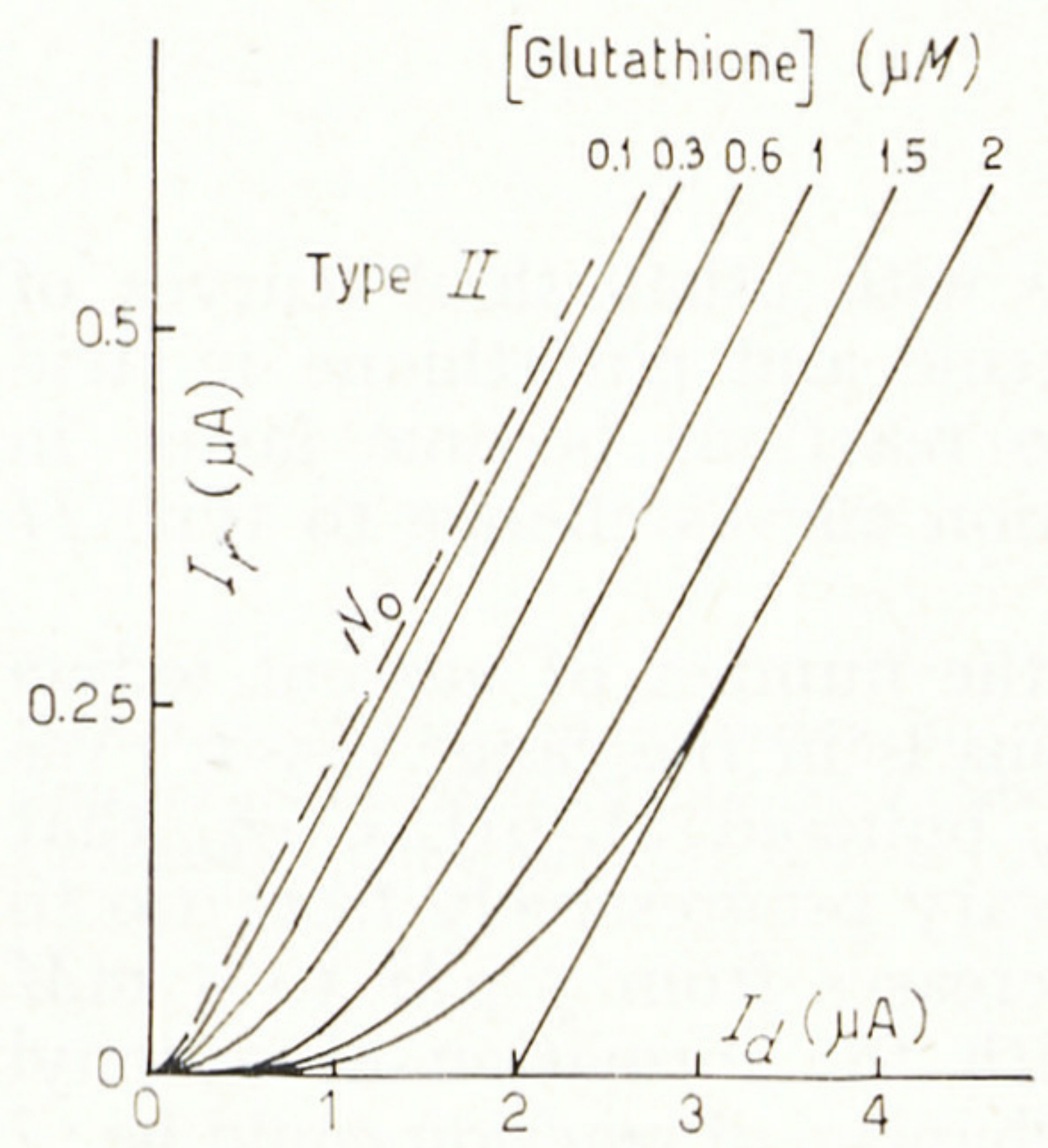

Fig. 5 .

Influence of glutathione concentration on its $I_{r}$ vs. $I_{d}$ titration curves by nascent bromine. $\mathrm{pH} 0.3, \mathrm{H}_{2} \mathrm{SO}_{4} 0.5 M$, KBr O.I $M, 20^{\circ} \mathrm{C}$.

Fig. 6.

Influence of glutathione concentration on the asymptote position $I_{d, o}$ of $I_{r} v s . I_{d}$ titration. curves by nascent bromine. $\mathrm{pH} 0.3, \mathrm{H}_{2} \mathrm{SO}_{4}$ $0.5 M$, $\mathrm{KBr}$ 0.r $M, 20{ }^{\circ} \mathrm{C}$. (O) scale as labelled; () divide each scale by 2.5 .

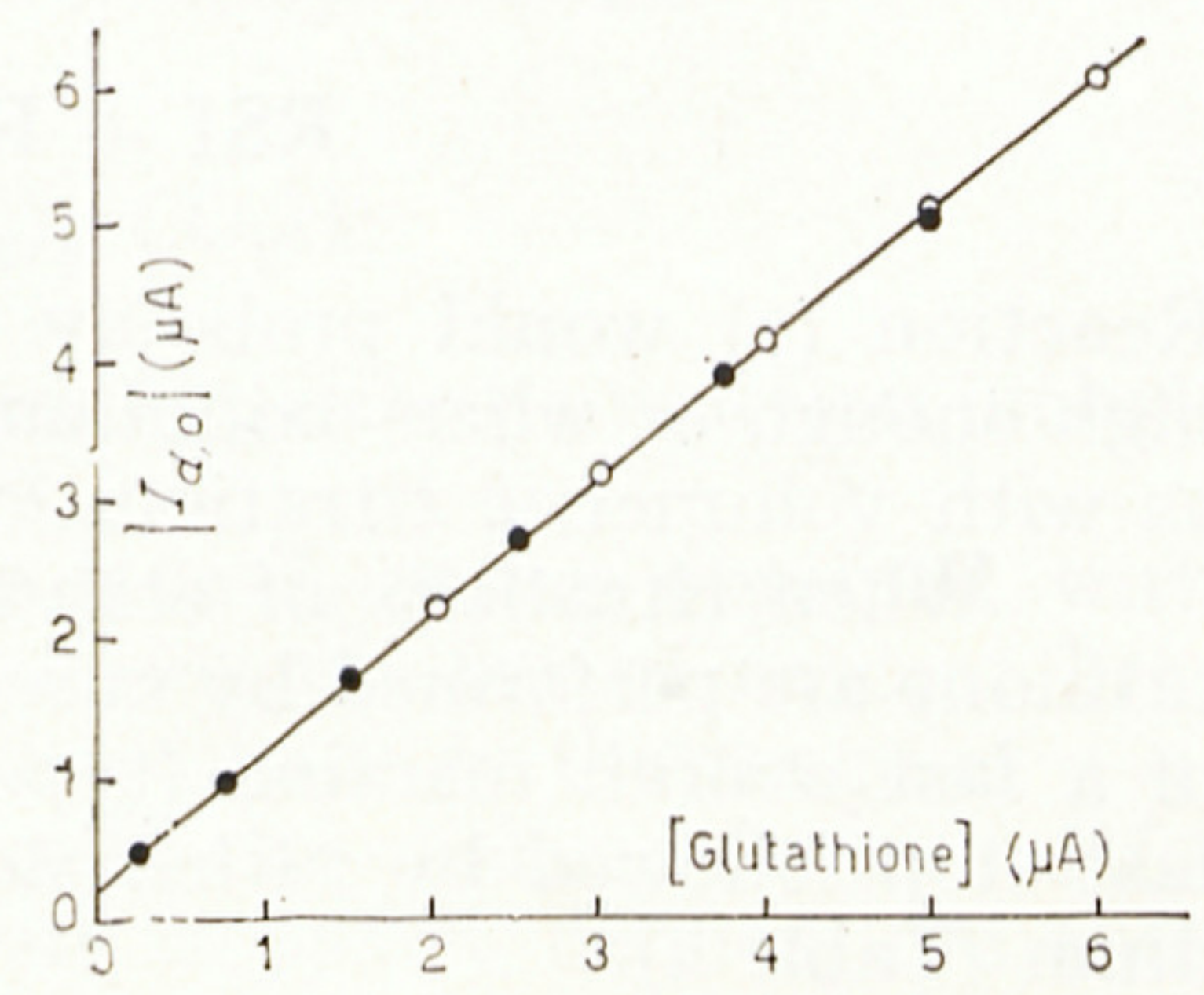




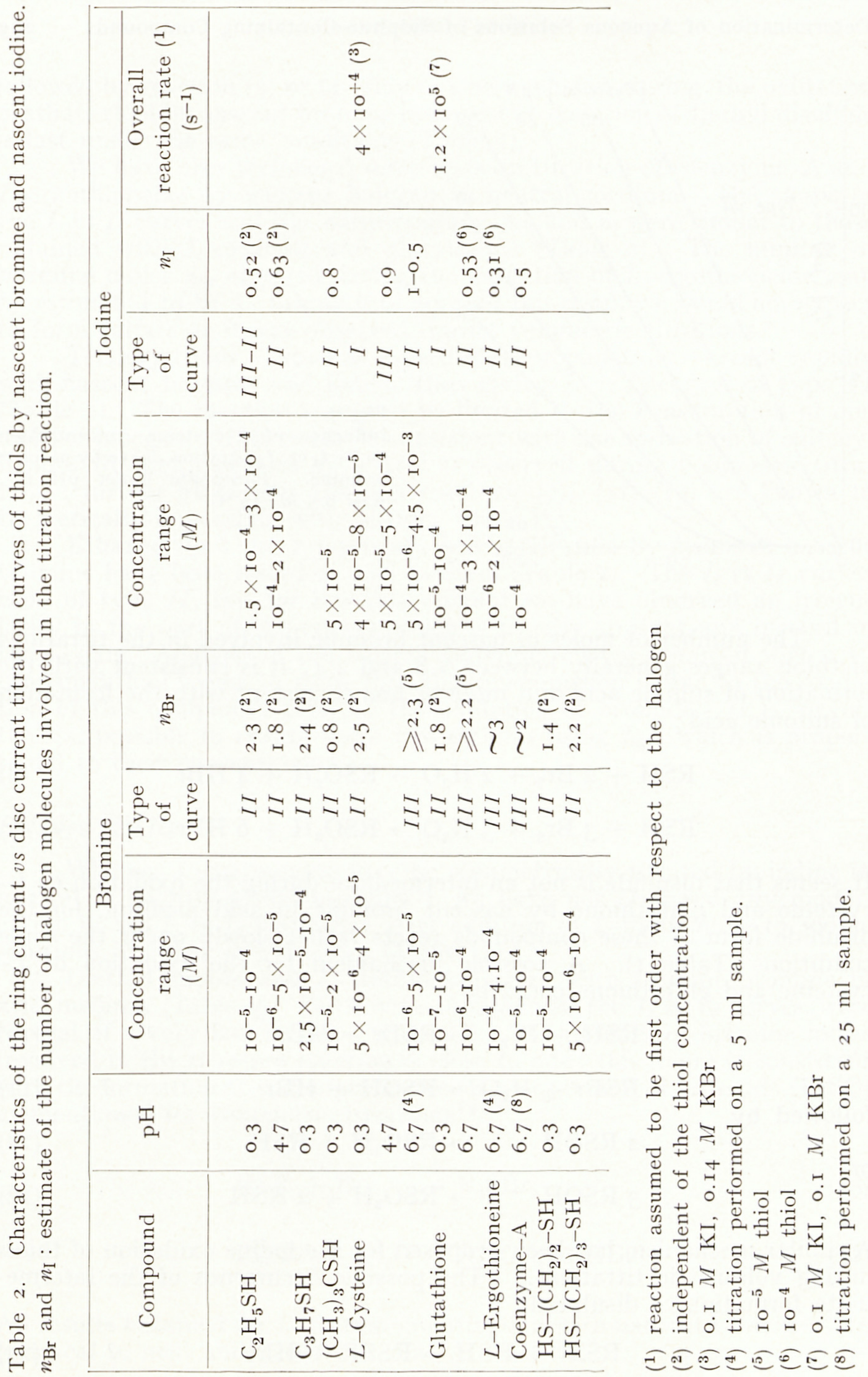




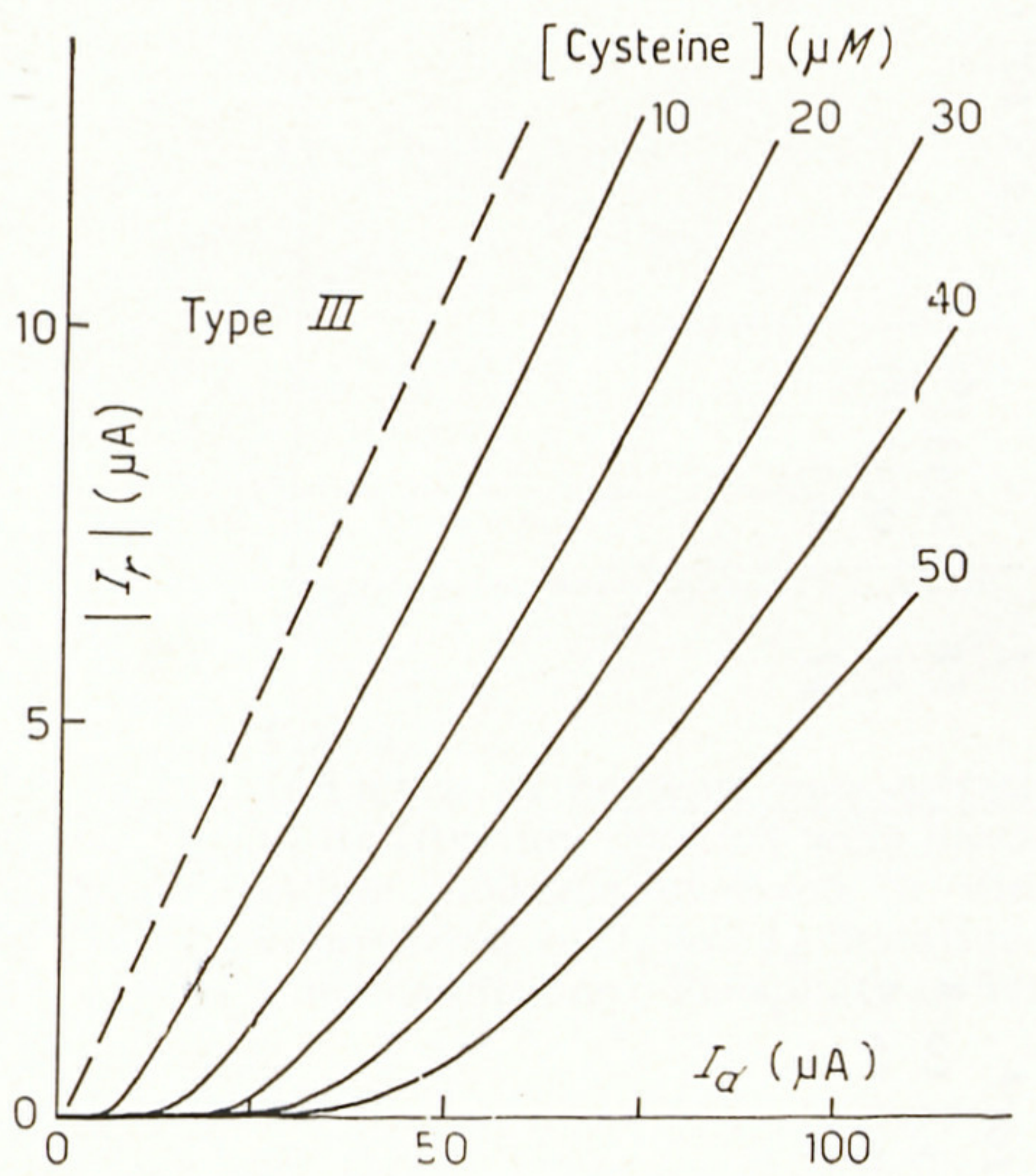

Fig. 7 .

Influence of $L$-cysteine concentration on its $I_{r} v s . I_{d}$ titration curve by nascent bromine. Phosphate buffer $\mathrm{pH}$ 6.7, $\mathrm{KBr} 0.5 M$, I $5{ }^{\circ} \mathrm{C}$.

The number of moles of nascent bromine involved in the titrations of thiols ranges generally between I.8 and 2.4 ; it is consistent with the formation of sulfinic acid and more or less consistent with the formation of sulfonic acid :

$$
\begin{aligned}
& \mathrm{RSH}+2 \mathrm{Br}_{2}+2 \mathrm{H}_{2} \mathrm{O} \rightarrow \mathrm{RSO}_{2} \mathrm{H}+4 \mathrm{HBr} \\
& \mathrm{RSH}+3 \mathrm{Br}_{2}+3 \mathrm{H}_{2} \mathrm{O} \rightarrow \mathrm{RSO}_{3} \mathrm{H}+6 \mathrm{HBr}
\end{aligned}
$$

It seems that disulfide is not an intermediate during the oxidation of $L-$ cysteine and glutathione by nascent bromine in acid medium, for the disulfide form of these compounds reacts rather slowly under the same conditions (Table I). A possible mechanism for the oxidation of $L-$ cysteine and glutathione could be :

followed by

$$
\begin{aligned}
& \mathrm{RSH}+\mathrm{Br}_{2} \rightarrow \mathrm{RSBr}+\mathrm{HBr} \\
& \mathrm{RSBr}+\mathrm{H}_{2} \mathrm{O} \rightarrow \mathrm{RSOH}+\mathrm{HBr}
\end{aligned}
$$

or

$$
2 \mathrm{RSOH} \rightarrow \mathrm{RSO}_{2} \mathrm{H}+\mathrm{RSH}
$$

$$
3 \mathrm{RSOH} \rightarrow \mathrm{RSO}_{3} \mathrm{H}+2 \mathrm{RSH}
$$

A similar mechanism has been proposed for the iodine oxidation of thiols during volumetric titrations. ${ }^{7}$ The possible occurrence of the intermediate formation of disulphide

$$
\mathrm{RSBr}+\mathrm{RSH} \rightarrow \mathrm{RSSR}+\mathrm{HBr}
$$


followed by reaction (3) or (4) may not be excluded during the oxidation of ethanethiol by nascent bromine because the oxidation of diethyl disulfide is fast under the same conditions (Table I).

We have also performed some tests on titration of coenzyme-A and $L$-ergothioneine by nascent halogen in neutral medium. The shape of the $I_{r}$ vs $I_{d}$ curves and the corresponding $n_{\mathrm{Br}}$ and $n_{\mathrm{I}}$ were similar to those obtained with $L$-cysteine and glutathione (Table 2). The number of bromine moles $n_{\mathrm{Br}}$ engaged during the oxidation of $L$-ergothioneine may be estimated to be 3 : taking into account this result we would not expect to form sulfate as it was observed during volumetric titrations. ${ }^{7}$

Tertiary thiols - such as 2 -methyl-2-propanethiol — react rapidly with nascent bromine and iodine, thus giving $I_{r}$ vs $I_{d}$ curves of type $I I$ (Table 2). The reaction seems to be limited to the consumption of one mole of halogen. This result is consistent with the formation of sulfenyl halides through reactions (6) or (I0) as observed during volumetric titrations: further oxidations through reactions (7), (II)-(I4) are known to be sterically impossible with tertiary thiols. ${ }^{14}$

Ethanedithiol and I,3-propanedithiol titration by means of nascent bromine have been tested in acid medium (Table 2). The $I_{\mathrm{r}}$ vs $I_{d}$ curves were of type $I I$, but for low-disc current we have observed an irregularity in the part of the curves which is usually straight and merged in the $I_{d}$ axis. Analysis of the current-potential curves obtained with I,3propanedithiol seems to show that this phenomenon is due to the oxidation of this compound prior to the oxidation of bromide. It is, nevertheless, possible to titrate these two dithiols using $I_{d, \mathrm{o}}$, which is proportional to their concentration.

\section{Sulfides $(R S R)$}

Whereas $L$-methionine may be volumetrically titrated by iodine in neutral or slightly acidic medium, ${ }^{15}$ we have not observed any modification in the $I_{r}$ vs $I_{d}$ blank line after addition of $L$-methionine to iodine solutions buffered at $\mathrm{pH}=6.7$ (Table 3 ).

Diethyl sulfide and $L$-methionine react with nascent bromine in acid medium (Table 3). With both compounds, the $I_{r}$ vs $I_{d}$ curves were typical of a very fast reaction (type $I I$ ). The number of bromine moles involved in the titration reaction is close to one : this figure is consistent with the formation of sulfonium halide $\left(\mathrm{R}_{2} \mathrm{SBr}_{2}\right)^{16}$ and of sulfoxide $\left(\mathrm{R}_{2} \mathrm{SO}\right)$ as mentioned for volumetric titrations ${ }^{13}$

$$
\begin{aligned}
& \mathrm{RSR}+\mathrm{Br}_{2} \rightarrow \mathrm{R}_{2} \mathrm{SBr}_{2} \\
& \mathrm{R}_{2} \mathrm{SBr}_{2}+\mathrm{H}_{2} \mathrm{O} \rightarrow \mathrm{R}_{2} \mathrm{SO}+2 \mathrm{HBr}
\end{aligned}
$$

All results obtained for $L$-methionine titration with nascent bromine were identical in acid and neutral media. 


\section{Proteins}

Cysteinyl, tyrosinyl, histidinyl, tryptophanyl, methionyl residues of proteins are known to react with iodine in aqueous solutions. ${ }^{10} \mathrm{We}$ have observed that free cysteine may be titrated by nascent iodine, whereas tyrosine, tryptophane ${ }^{17}$ and methionine do not react under similar conditions. We have attempted to use this possibility to perform ring-disc electrode titration of ovalbumine, which contains 3-4 cysteinyl residues and is known to react with 3 moles of iodide. ${ }^{18}$ No modification of the blank line $I_{r}$ vs $I_{d}$ was observed when Io $\mu M$ ovalbumine was added to a $\mathrm{pH}=6.7$ solution of iodine (Table 3 ). This result is probably related to the decrease of the reaction rate of cysteine when linked tothe protein.

On the contrary, the $I_{r}$ rs $I_{d}$ titration curves of 2 -IO $\mu M$ ovalbumine by nascent bromine show that reactions occur both in acid and neutral media (Table 3). As these curves belong to type $I I I$, their asymptote is not well defined and the number $n_{\mathrm{Br}}$ of bromine molecules involved may be estimated to be at least 20. This figure is smaller than the value, one could predict on the basis of the number of cysteinyl, cystinyl and methionyl residues assumed to be present in ovalbumine, i.e. respectively $3^{-4}$, I and $5_{5}{ }^{18}$, and to the $n_{\mathrm{Br}}$ value measured for the corresponding amino-acids, i.e. respectively $2-3, c a$. Io and I (Tables I and 2). In such a comparison, one has not to take into account the tyrosinyl and hystidyl residues which, like their corresponding amino-acids, would react more or less slowly with nascent bromine. ${ }^{17}$

\section{Thiol ester $\left(R C O S R^{\prime}\right)$}

Ring-disc electrode determination of ethylthioacetate and of acetylcoenzyme-A has been tested. Neither of these compounds was found to react with nascent iodine. On the contrary, the $I_{r}$ vs $I_{d}$ titration curves of both compounds by nascent bromine indicate a rather slow reaction (type I) (Table 3). Reaction rate of ethylthioacetate with nascent bromine does not seem to depend very much on the $\mathrm{pH}$.

\section{Various inorganic sulfur-containing compounds}

We made a few tests on acid solutions of sulfhydric acid, sulfur dioxide and thiosulfate ions in order to see if ring-disc electrodes could be used to titrate these compounds. The reaction between nascent bromine and sulfhydric acid is quantitative during the transit time from the disc to the ring and gives very well defined $I_{r}$ vs $I_{d}$ curves, typical of a very fast reaction (type $I I$ ) (Table 4 ) : the position $I_{d, \mathrm{o}}$ of their asymptote is proportional to the sulfhydric acid concentration when the evaporation of this compound (less than I $\% \mathrm{~min}^{-1}$ for a o.I $\mathrm{m} M$ solution) is taken into account. The number of nascent bromine molecules engaged in this reaction equals 4.0 , which is consistent with the formation of sulfate ions, as it occurs in volumetric titrations. ${ }^{19}$ Reaction of thiosulfate ions with nascent iodine (regardless of its slow disproportionation to sulfide and sulfur) ${ }^{19}$ and of sulfur dioxide with nascent bromine regardless of its slow evaporation) give $I_{r} v s I_{d}$ curves of type $I I I$. 
Table 3. Characteristics of the ring current vs disc current titration curves of organic sulfides, ovalbumine, ethylthioacetate and acetylcoenzyme A. $n_{\mathrm{Br}}$ : estimate of the number of bromine molecules involved in the titration reaction.

\begin{tabular}{|c|c|c|c|c|c|c|}
\hline \multirow[b]{2}{*}{ Compound } & \multirow[b]{2}{*}{$\mathrm{pH}$} & \multicolumn{3}{|c|}{ Bromine } & \multicolumn{2}{|c|}{ Iodine } \\
\hline & & $\begin{array}{c}\text { Concentration } \\
\text { range } \\
(M)\end{array}$ & $\begin{array}{l}\text { Type } \\
\text { of } \\
\text { curve }\end{array}$ & $n_{\mathrm{Br}}$ & $\begin{array}{c}\text { Concentration } \\
\text { range } \\
(M)\end{array}$ & $\begin{array}{l}\text { Overall } \\
\text { reaction } \\
\text { rate }\end{array}$ \\
\hline$L$-Methionine & $\begin{array}{l}0.3 \\
6.7\end{array}$ & $\begin{array}{l}\mathrm{IO}^{-5}-5 \times \mathrm{IO}^{-5} \\
\mathrm{IO}^{-5}-\mathrm{IO}^{-4}\end{array}$ & $\begin{array}{l}I I \\
I I\end{array}$ & $\begin{array}{l}0.8\left({ }^{1}\right) \\
0.8(1)\end{array}$ & $\begin{array}{c}5 \times \mathrm{IO}^{-5} \\
\mathrm{IO}^{-4}-2 \times \mathrm{IO}^{-4}\end{array}$ & $\begin{array}{l}\text { no noticeable } \\
\text { reaction } \\
\text { id. }\end{array}$ \\
\hline $\mathrm{C}_{2} \mathrm{H}_{5}-\mathrm{S}-\mathrm{C}_{2} \mathrm{H}_{5}$ & 0.3 & $2.5 \times \mathrm{IO}^{-6}-3 \times \mathrm{IO}^{-5}$ & $I I$ & I.O $(1)$ & & \\
\hline Ovalbumine & $\begin{array}{l}0.3 \\
6.7\end{array}$ & $\begin{array}{l}2 \times \mathrm{IO}^{-5} \\
2 \times \mathrm{IO}^{-6}-\mathrm{IO}^{-5}\end{array}$ & $\begin{array}{l}I I I \\
I I I\end{array}$ & $\sim_{20}$ & $\mathrm{IO}^{-5}$ & id. \\
\hline $\mathrm{CH}_{3}-\mathrm{COS}-\mathrm{C}_{2} \mathrm{H}_{5}$ & $\begin{array}{l}0.3 \\
5.0 \\
5.6 \\
6.7\end{array}$ & $\begin{array}{l}\mathrm{IO}^{-5}-\mathrm{IO}^{-4} \\
\mathrm{IO}^{-5}-\mathrm{IO}^{-4} \\
\mathrm{IO}^{-5}-\mathrm{IO}^{-4} \\
\mathrm{IO}^{-5}-\mathrm{IO}^{-4}\end{array}$ & $\begin{array}{r}I \\
I I I \\
I I I \\
I I I\end{array}$ & & $\begin{array}{l}\mathrm{IO}^{-4} \\
\mathrm{IO}^{-4} \\
\mathrm{IO}^{-4}\end{array}$ & $\begin{array}{l}\text { id. } \\
\text { id. } \\
\text { id. }\end{array}$ \\
\hline $\begin{array}{l}\text { Acetyl- } \\
\text { coenzyme A }\left({ }^{2}\right)\end{array}$ & 6.7 & $\mathrm{IO}^{-5}-5 \times \mathrm{IO}^{-5}$ & $I$ & & $5 \times \mathrm{IO}^{-5}$ & id. \\
\hline
\end{tabular}

(1) independent of the concentration of titrated compound

$\left({ }^{2}\right)$ titration carried out on a $25 \mathrm{ml}$ sample.

Table 4. Characteristics of the ring current vs disc current titration curves of some inorganic sulfur-containing compounds. $n_{\mathrm{Br}}$ and $n_{\mathrm{I}}$ : estimate of the number of halogen molecules involved in the titration reaction.

\begin{tabular}{|c|c|c|c|c|c|c|c|}
\hline \multirow[b]{2}{*}{ Compound } & \multirow[b]{2}{*}{$\mathrm{pH}$} & \multicolumn{3}{|c|}{ Bromine } & \multicolumn{3}{|c|}{ Iodine } \\
\hline & & $\begin{array}{c}\text { Concentration } \\
\text { range } \\
(M)\end{array}$ & $\begin{array}{l}\text { Type } \\
\text { of } \\
\text { curve }\end{array}$ & $n_{\mathrm{Br}}$ & $\begin{array}{l}\text { Concentration } \\
\text { range } \\
(M)\end{array}$ & $\begin{array}{l}\text { Type } \\
\text { of } \\
\text { curve }\end{array}$ & $n_{\mathrm{I}}$ \\
\hline Sulfhydric acid & 0.3 & $3 \times \mathrm{IO}^{-5}-\mathrm{IO}^{-4}$ & $I I$ & $4.0{ }^{(1)}$ & & & \\
\hline Thiosulfate & 0.3 & & & & $\mathrm{IO}^{-4}-8 \times \mathrm{IO}^{-4}$ & $I I I$ & $\sim_{0.9}\left({ }^{2}\right)$ \\
\hline $\mathrm{SO}_{2}, \mathrm{HSO}_{3}^{-}$ & 0.3 & $\mathrm{IO}^{-6}-\mathrm{IO}^{-4}$ & $I I I$ & & & & \\
\hline
\end{tabular}

(1) independent of the concentration of titrated compound

(2) Io $^{-4} M$ thiosulfate 


\section{Conclusion}

The use of ring-disc electrodes may be a convenient method for the determination of aqueous solutions of sulfur-containing compounds which react rapidly enough with electrochemically generated and detected bromine or iodine. The ring current vs disc current titration curves may present different shapes (Fig. I) : we propose a classification into three types according to the rate of the reactions involved and to the way the $I_{r}$ vs $I_{d}$ curves have to be analysed to determine the concentration.

Titration curves of type $I I$ correspond to very fast reactions and present a well defined asymptote (Fig. 5) : its intersection $I_{d, \mathrm{o}}$ with the disc current axis is proportional to the concentration of the analysed compound (Fig. 6). Detection limits are usually around o.I $\mu M$ : they are determined by the purity of buffered halide solutions and by the background noise (stability of background curve, contact and electronic noise). An accuracy of a few per cent is usual when the concentration to determine is larger than about $5 \mu M$. Titrations of this type are possible for dimethyl- and diethyl disulfides, ethanethiol, I-propanethiol, 2-methyl2-propanethiol, L-cysteine, glutathione, ethanedithiol, I,3-propanedithiol $L$-methionine, diethylsulfide and sulfhydric acid.

Titration curves of type $I$ correspond to rather slow reactions: their slope $N_{K}$ near the origin is related to the concentration (Fig. 2). Determination of the unknown concentration requires the construction of a calibration curve $N_{K}$ vs. $c$ for every analysed compound (Fig. 3). In this case, the detection limits depend on the rate of the titration reactions : a concentration as low as about I $\mu M$ can be detected in the case of $L$-cystine and one as low as Io $\mu M$ in the case of the disulfide form of glutathione. An accuracy of a few per cent is obtained when the slope near the origin is in the $0.2 N_{0}-0.8 N_{0}$ range : $N_{0}$ is the slope of the blank line obtained with a pure buffered halide solution. The corresponding concentration range is approximatively 3-30 times the detection limit.

Titration curves of type $I I I$ are intermediate between $I I$ and $I$ : their asymptote is not well defined and their slope near the origin is too small to be measured (Fig. 7). Determination of an unknown concentration is still possible, but it requires the comparison with a set of $I_{r} v s I_{d}$ curves obtained with solutions of known concentration. The detection limits are around I $\mu M$ for the disulfide form of $D L-\alpha-$ lipoïc acid, $L-$ ergothioneine, coenzyme $\mathrm{A}$, ovalbumine, sulfur dioxide, and Io $\mu M$ for ethylthioacetate, acetyl coenzyme-A and thiosulfate ions.

The shape of the ring-current $v s$ disc current titration curves may be altered by modifying the parameters affecting the reaction rate, i.e. $\mathrm{pH}$, temperature, rotation rate of the electrode, halide nature and concentration, titrated compound concentration. Their classification is thus sometimes difficult because curves of type $I$ or $I I I$ may change continuously to type $I I$. Of course, the parameters listed above can be chosen so that the titration reaction is the fastest. For example, titrations by means of nascent bromine are more sensitive than those performed with nascent iodine for all compounds studied. 
Since any chemical reacting with the halogen can be titrated, the method is not specific. However, in simple mixtures it may be possible to choose a set of experimental parameters so that only one compound is titrated under certain conditions. For example, at $\mathrm{pH}=0.3, L_{-}$ cysteine alone can be titrated by nascent iodine in a mixture of any amino-acids of similar concentration : even tryptophane, tyrosine, histidine, methionine and cystine do not interfere with this reaction. Similarly, acid or neutral solutions of thiols can be determined in the presence of thiol esters when nascent iodine is used.

The use of ring-disc electrodes may also give information concerning mechanisms and kinetics of reactions with bromine and iodine. The number $n_{\mathrm{Br}}$ or $n_{\mathrm{I}}$ of involved halogen molecules may be estimated when the $I_{\mathrm{r}}$ vs $I_{d}$ curves present a rather well-defined asymptote. This is impossible with curves of type $I$ and lead to underestimated values in the case of curves of type $I I I$. When such determinations are possible, i.e. with curves of type $I I$, the $n_{\mathrm{Br}}$ and $n_{\mathrm{I}}$ values are sometimes close to those obtained by volumetric titrations (2-methyl-2-propanethiol, diethylsulfide, $L$-methionine and sulfhydric acid) ; they are however, significantly lower (ethane- and I-propanethiol, L-cysteine, glutathione, ethanedithiol, I,3-propanedithiol) when the complete reaction time is much longer than the transit time from the disc to the ring ( $18 \mathrm{~ms}$ ). On the other hand, the apparent rate of the titration reaction may be estimated from the slope $N_{\mathrm{K}}$ of the titration curves of type $I$ : variation of the halide concentration and thus of the $\left[\mathrm{X}_{3}^{-}\right] /\left[\mathrm{X}_{2}\right]$ ratio allows the determination of the rate constants relative to $\mathrm{X}_{3}{ }^{-}$and to $\mathrm{X}_{2} .{ }^{2 b}$ Furthermore, the use of $n_{\mathrm{Br}}$ or $n_{\mathrm{I}}$ and the kinetics of the reaction may give information concerning the mechanisms of reaction: we have shown, for example, that oxydation of $L$-cysteine and glutathione by nascent bromine in acid media should not proceed with the intermediate formation of disulfide.

Finally, the characteristics of ring-disc electrode titrations may be compared either with classical voltammetric measurements or with simple volumetries. Their most obvious interest consists in the replacement of slow or impossible electrochemical oxidation by fast chemical reaction and in its high sensitivity (till $5 \times 10^{-10}$ mole) for a non destructive method.

\section{Acknowledgement}

This work was supported by the „Centre National de la Recherche Scientifique" ERA no 469 and by "Electricité de France".

\section{References}

1a F. Rauwel and D.R. Thévenot, J. Appl. Electrochem. 6, ing (i976)

$1 b$ F. Rauwel, Thesis of Docteur-Ingénieur, University Paris VI, France (I975), C.N.R.S. registration number A.O. I 1382 
2 W.J. Albery and M.L. Hitchman, in Ring-Disc Electrodes, Science Research Papers, Clarendon Press Oxford (r97I) : $a$ Chap. 7, p. $99 ; b$ Chap. 9, p. I22; c Chap. 3, p. I7

3 W.J. Albery and S. Bruckenstein, Trans. Faraday Soc. 62, igzo (ig66)

4 I.M. Kolthoff and J.J. Lingane, in Polarography, Interscience, New York and London (I952) 2nd Ed., p. 53

5 W.J. Albery, M.L. Hitchman and J. Ulstrup, Trans. Faraday Soc. 64, 283 I (I968)

6 R.N. Adams, in Electrochemistry at solid electrodes, M. Dekker, New York, N.Y. (I969) p. I24

7 P.C. Jocelyn, in Biochemistry of the SH group, Academic Press, London and New York (I972) p. I03

8 L. Genevois and J. Baraud, Chim. Anal. Paris 38, 87 (i956)

9 J. Baraud and L. Genevois, Bull. Soc. Chim. Fr. 1955, i 499

10 A.N. Glazer, Ann. Rev. Biochem. 39, io2 (I970)

11 K. Shinohara and M. Kilpatrick, J. Am. Chem. Soc. 56, I466 (i934)

12 A. Fontana and C. Toniolo, in Chemistry of the thiol group, S. Patai, (Editor) John Wiley, London (I974) vol. I, p. 30I

13 J. Siggia and R.L. Edsberg, Ind. Eng. Chem., Anal. Ed. 20, 938 (I948)

14 I.M. Kolthoff and W.E. Harris, Anal. Chem. 21, 963 (i949)

15 J.P. Greenstein and M. Winitz, in Chemistry of the amino acids, John Wiley and Sons, New York, London (I96I) p. 2I32

16 V. Grignard, in Précis de Chimie Organique, Masson, 4th Ed. (I958) p. 406

17 F. RAUWEL, unpublished results

18 R. Cecil, in The Proteins, H. Neurath (Editor), Academic Press, New York and London (I963) vol. I, p. 388

19 G. Charlot, in L'analyse qualitative et les réactions en solution, Masson (I963), 5th Ed., p. 359 